\title{
NONLINEAR PREDICTIVE CONTROL OF WIND ENERGY CONVERSION SYSTEM USING DFIG WITH AERODYNAMIC TORQUE OBSERVER
}

\author{
Kamel Ouari ${ }^{*}$ - Mohand Ouhrouche ${ }^{* *}$ \\ Toufik Rekioua* — Taib Nabil*
}

\begin{abstract}
In order to improvement of the performances for wind energy conversions systems (WECS), an advanced control techniques must be used. In this paper, as an alternative to conventional PI-type control methods, a nonlinear predictive control (NPC) approach is developed for DFIG-based wind turbine. To enhance the robustness of the controller, a disturbance observer is designed to estimate the aerodynamic torque which is considered as an unknown perturbation. An explicitly analytical form of the optimal predictive controller is given consequently on-line optimization is not necessary The DFIG is fed through the rotor windings by a back-to-back converter controlled by Pulse Width Modulation (PWM), where the stator winding is directly connected to the grid. The presented simulation results show a good performance in trajectory tracking of the proposed strategy and rejection of disturbances is successfully achieved.
\end{abstract}

K e y w or ds: nonlinear predictive control, DFIG-based wind turbine, disturbance observer

\section{INTRODUCTION}

The control of the variable speed wind turbines based on the doubly fed induction generator (DFIG) is a difficult engineering problem since: the induction machines are highly coupled, fast dynamics and nonlinear multivariable system. On the other hand, the wind turbine has strong nonlinear characteristics and the aerodynamic torque change frequently.

The Field-oriented vector control using cascaded PI controllers is widely used, in DFIG-based wind turbines, for reasons of simplicity and applicability [1]. However, PI-type control methods are not robust enough to accommodate the variations of external disturbances, parameters, and perturbations during operation. To overcome these drawbacks, various approaches have been proposed to replace PI-type controllers. Some examples are the $\mathrm{H}_{\infty}$ control theory, neural networks and sliding mode control $[2-4]$.

Nowadays, nonlinear model predictive control (NMPC) refers to a class of computer control algorithms that utilize an explicit process model to predict the future response of a plant. Due to its good robustness for external disturbances and varying parameters, it has received a great deal of attention and is considered by many to be one of the most promising methods in control engineering $[5,6]$.

Several control strategies using linear and nonlinear MPC have been proposed in the technical literature [7-11]. In [7] Chen et al have designed a nonlinear predictive control law for multi-variable nonlinear systems based on Taylor series expansion, where the same relative degree of multi-input and multi-output system is considered. Hedjar, in [8], have proposed a cascaded NPC based on Taylor series. A predictive current control (PCC) strategy for doubly fed induction generators has been treated in [9]. However, the high performance can be achieved accurately only when the load torque disturbance and the parameters variation are well known. Multi-variable control strategy based on MPC techniques has been proposed for wind turbines based on DFIG in [10].Generalized predictive control (GPC) has been used to control the pitch angle of windmill blades in order to reduce power fluctuations in [11]. However, these methods achieve a high performance only when the aerodynamic torque is well known.

In order to provide powerful abilities in handling system disturbances and improving robustness, the nonlinear predictive control must be combined with a disturbance observer [12].

For improvement, in this paper, the rotor speed and electromagnetic torque are controlled by the rotor side converter (RSC), while the power transited to the grid is controlled by the grid side converter (GSC). A cascaded NPC and stator-field-oriented control are investigated. In addition, an aerodynamic torque observer, defined from predictive control, is integrated into the control law in order to enhance the robustness of the controller.

The rest of the paper is organized as follows: In Section 2 , the dynamic model of wind energy conversion system is exposed. In Section 3, mathematical formulation of NPC for nonlinear system is presented. The control system is developed is Section 4. The simulation results are given in Sections 5. Finally, Section 6 concludes the paper.

\footnotetext{
* Laboratory LTII, University of Bejaia, Algeria ${ }^{* *}$ Laboratory LICOME, University of Quebec at Chicoutimi, Canada, ouari.kamel@ymail.com, Mohand_ouhrouche@uqac.ca, to_reki@yahoo.fr, taib_nabil@yahoo.fr
} 


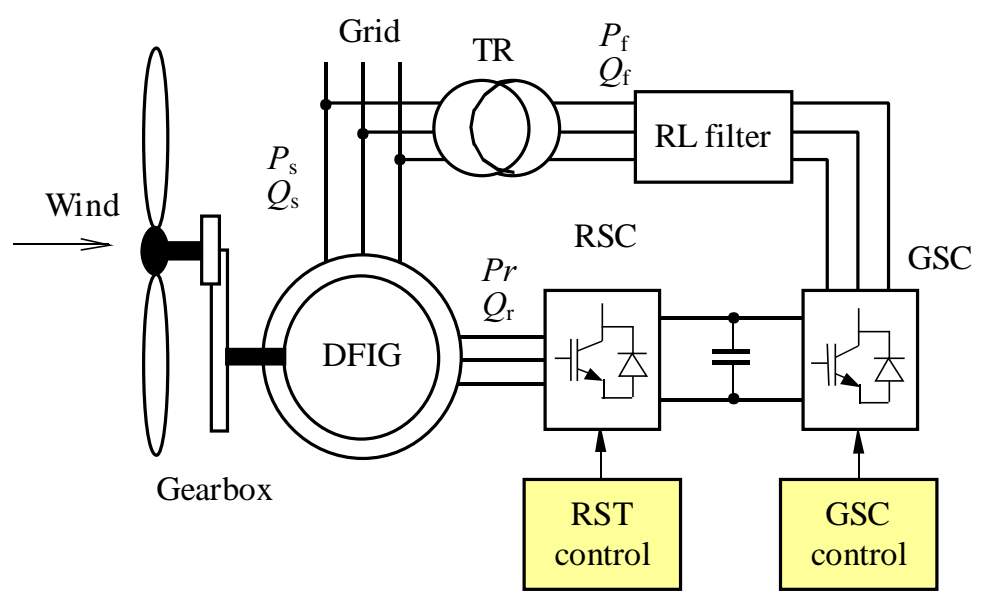

Fig. 1. System configuration

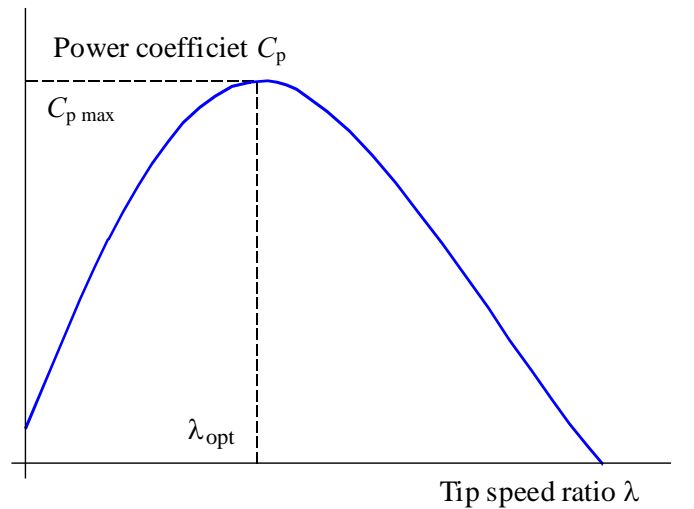

Fig. 2. Typical power coefficient

\section{WIND GENERATION SYSTEM MODEL}

The system considered in this work is shown in Fig. 1.

\subsection{Modeling of the Wind Turbine}

The aerodynamic power extracted from the wind can be expressed as

$$
P_{t}=\frac{1}{2} \rho_{a} \pi R^{2} C_{p}(\lambda, \beta) v^{3} .
$$

The coefficient $C_{p}$ is specific for each wind turbine. The tip speed ratio is defined as

$$
\lambda=\frac{\Omega_{t} R}{\nu} .
$$

A typical relationship between $C_{p}$ and $\lambda$ is shown in Fig. 2.

At the point $\lambda_{o p t}, C_{p}=C_{p-\max }$, the maximum power can be extracted. To this end

- the blades pitch angle, $\beta$, is fixed at its optimal value $\beta_{C_{p-\max }}$,

- the turbine speed is controlled to tracks its reference $\Omega_{t-r e f}$ given by equation (3), thus the tip-speed ratio, $\lambda$, is maintained at its optimal value $\lambda_{o p t}$.

$$
\Omega_{t-r e f}=\frac{\lambda_{o p t}}{R} v
$$

Then the rotor speed and active grid power references are given by

$$
\begin{aligned}
\Omega_{\text {r-ref }} & =\frac{\lambda_{o p t} G}{R} v, \\
P_{\text {grid-ref }} & =\frac{1}{2} \eta \rho_{a} \pi^{2} C_{p-\max } v^{3} .
\end{aligned}
$$

Neglecting the transmission losses, the torque and speed of the wind turbine, referred to the generator side of the gearbox, are given by

$$
T_{r}=\frac{T_{t}}{G}, \quad \Omega_{t}=\frac{\Omega_{r}}{G} .
$$

\subsection{DFIG model}

By choosing a $\mathrm{d}-\mathrm{q}$ reference frame synchronized with the stator flux, by setting the quadratic component of the stator flux to the null value and by neglecting the stator resistance, the electrical equation of the DFIG is written as follows $[13,14]$.

$$
\begin{array}{r}
\frac{\mathrm{d} I_{d r}}{\mathrm{~d} t}=-\frac{R_{r}}{\sigma L_{r}} I_{d r}+s \omega_{s} I_{q r}+\frac{1}{\sigma L_{r}} V_{d r}, \\
\frac{\mathrm{d} I_{q r}}{\mathrm{~d} t}=-\frac{R_{r}}{\sigma L_{r}} I_{q r}-s \omega_{s} I_{d r}+s \frac{M V_{s}}{\sigma L_{r} L_{s}}+\frac{1}{\sigma L_{r}} V_{q r} .
\end{array}
$$

The electrical model is completed by the mechanical equation given below

$$
J \frac{\mathrm{d}}{\mathrm{d} t} \Omega_{r}=T_{e m}-T_{r}-f_{r} \Omega_{r} .
$$

The electromagnetic torque generated by the DFIG is given by

$$
T_{e m}=P \frac{M V_{s}}{\omega_{s} L_{s}} I_{q r} .
$$

The MADA active and reactive powers can be expressed as follows

$$
\begin{aligned}
P_{s} & =-\frac{M V_{s}}{L_{s}} I_{q r} \\
Q_{s} & =\frac{V_{s}^{2}}{\omega_{s} L_{s}}-\frac{M V_{s}}{L_{s}} I_{d r}
\end{aligned}
$$




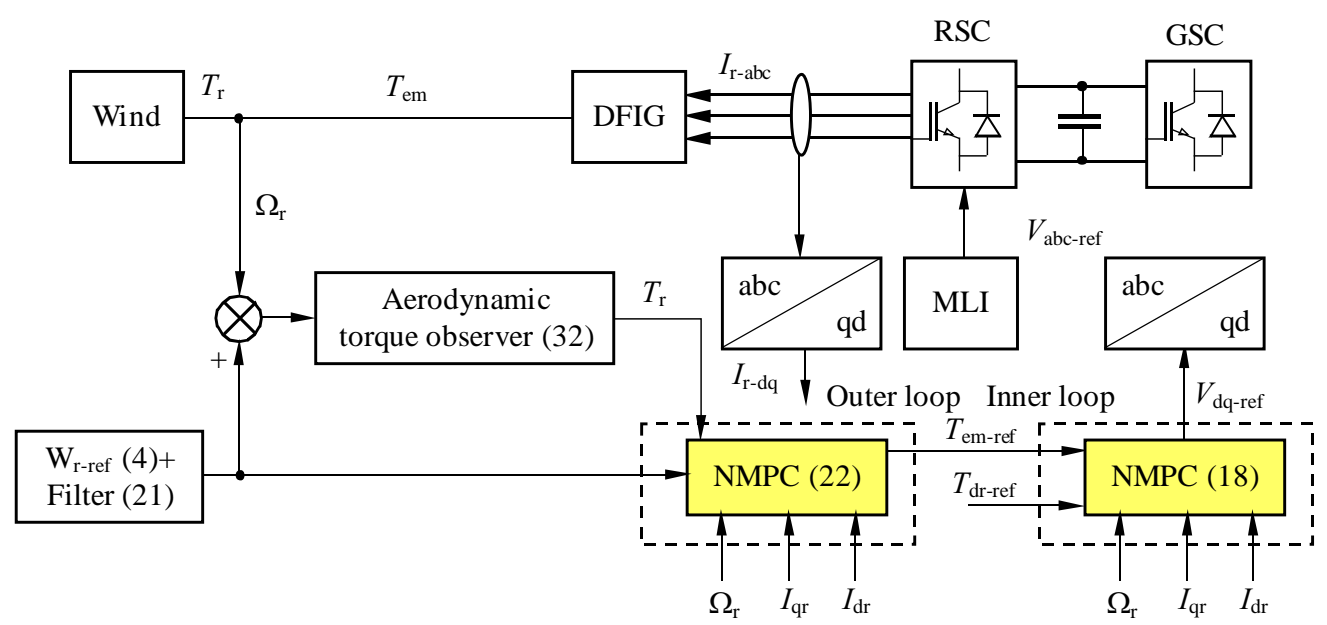

Fig. 3. Block Diagram of the proposed NMPC applied to the RSC

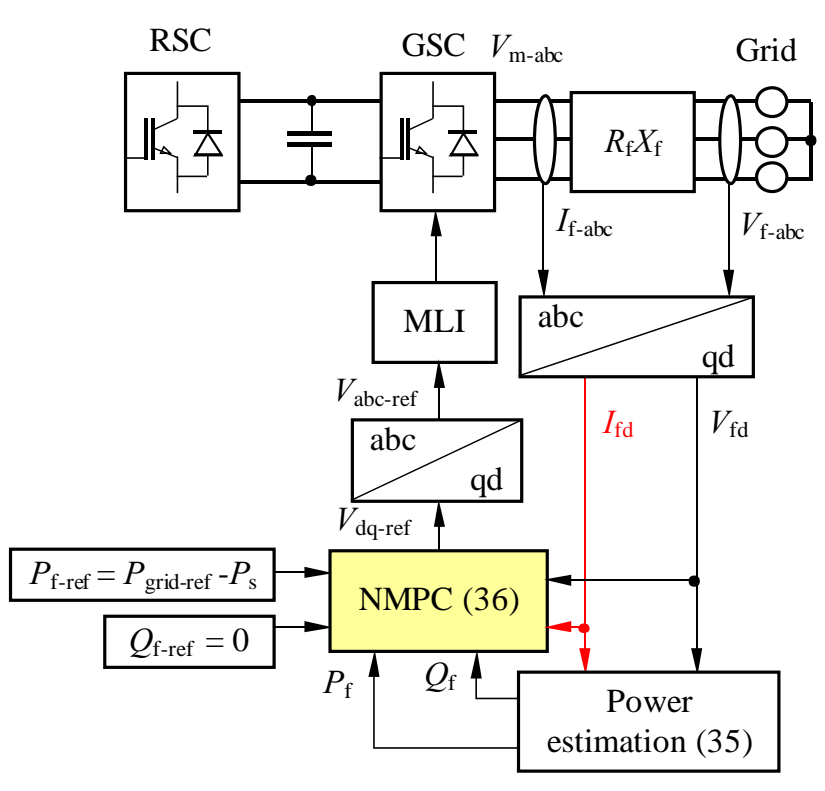

Fig. 4. Block Diagram of the proposed NPC applied to the GSC

with $\quad \sigma=1-\frac{M}{L_{r} L_{s}}, \quad s=\frac{\omega_{s}-\omega_{r}}{\omega_{s}}$.

The active and reactive powers transited to the grid are

$$
P_{\text {grid }}=P_{s}+P_{f}, \quad Q_{\text {grid }}=Q_{s}+Q_{f} .
$$

\section{MATHEMATICAL FORMULATION OF NPC}

The nonlinear model predictive control proposed by Chen et al [7] is briefly described in this section. We consider a nonlinear system of the form

$$
\begin{aligned}
\dot{x}(t) & =f(x)+g_{u}(x) u(t)+g_{T}(x) T_{r}(t), \\
Y & =h(x)
\end{aligned}
$$

where $x \in \Re^{n}$ is the state space vector, $u \in \Re^{m}$ is the control input and $T_{r} \in \Re$ is the external disturbance. The function $f(x)$ and $h(x)$ are assumed to be continuously differentiable a sufficient number of times. Vector function $g_{u}(x)$ and $g_{T}(x)$ are continuous functions of $x$. The problem consists in elaborating a control law $u(t)$ such that the output $y(t+\tau)$ can optimally track a desired reference $y_{r}(t+\tau)$ in presence of the disturbance $T_{r}$. The predictive control will be optimal if the finite horizon cost function $\Im$ is minimized

$$
\Im=\frac{1}{2} \int_{0}^{T p}\left[y(t+\tau)-y_{r}(+\tau)\right]^{\top}\left[y(t+\tau)-y_{r}(+\tau)\right] \mathrm{d} \tau
$$

To solve the nonlinear optimization problem (12), the predicted output $y(t+\tau)$ and the predicted reference $y_{r}(t+\tau)$ are approximated by Taylor series expansion

$$
\begin{aligned}
y_{i}(t+\tau)=h_{i}(x)+\sum_{k=1}^{\rho_{i}} & \frac{\tau^{k}}{k !} L_{f}^{k} h_{i}(x) \\
& +\frac{\tau^{\rho_{i}}}{\rho_{i} !} L_{g u} L_{f}^{\left(\rho_{i}-1\right)} h_{i}(x) u(t) .
\end{aligned}
$$

The Lie derivative of function $h_{i}(x)$ along a vector field $f(x)=\left(f_{1}(x), \ldots, f_{n}(x)\right)$ is denoted by

$$
\begin{aligned}
L_{f} h_{i}(x) & =\frac{\partial h_{i}(x)}{\partial x} f(x), \\
L_{f}^{k} h_{i}(x) & =L_{f}\left(L_{f}^{(k-1)} h_{i}(x)\right), \\
L_{g_{u}} L_{f} h_{i}(x) & =\frac{\partial L_{f} h_{i}(x)}{\partial x} g_{u}(x), \\
L_{g_{T}} L_{f} h_{i}(x) & =\frac{\partial L_{f} h_{i}(x)}{\partial x} g_{T}(x) .
\end{aligned}
$$

The necessary condition for the optimal control is given by

$$
\frac{\mathrm{d} \Im}{\mathrm{d} u}=0
$$




\section{THE CONTROL SYSTEM}

The rotor speed is controlled by the rotor side converter (RSC), while the power flow is controlled by the grid side converter (GSC).

\subsection{Rotor side converter control}

As DFIG is characterized by two-time scales modes, $i e$ electrical (fast) and mechanical (slow) modes, a cascaded structure is adopted for the design of the controller, see Fig. 3. The proposed control law is based on two points: NPC-based torque-current control loop generating the rotor reference voltage and NPC-based speed control loop that provides the torque reference.

\subsubsection{Inner control loop}

In the internal loop, the predictive control is applied to the electrical equations in order to provide the components of the armature rotor voltage $\left(\mathrm{V}_{\mathrm{d}-\mathrm{ref}}, \mathrm{V}_{\mathrm{qd}-\mathrm{ref}}\right)$. From equation (6), it follows that the electrical equations can be expressed as

$$
\begin{aligned}
\dot{x}(t) & =f(x)+g_{u}(x) u(t), \\
Y & =h(x)
\end{aligned}
$$

with

$x=\left(\begin{array}{ll}I_{d r} & I_{q r}\end{array}\right)^{\top}, u=\left(\begin{array}{ll}V_{d r-r e f} & V_{q r-r e f}\end{array}\right)^{\top}, y=\left(\begin{array}{ll}T_{e m} & I_{d r}\end{array}\right)^{\top}$.

The state vector $x$ is composed of the d-axis and qaxis component of the armature rotor currents. The input vector $u$ is made of the $\mathrm{d}$-axis and q-axis components of the armature rotor voltage. The output vector y consists of the electromagnetic torque and the d-axis rotor current, while vector function $f(x)$ and $g_{u}(x)$ are defined as

$$
\begin{gathered}
f(x)=\left(\begin{array}{c}
-\frac{R_{r}}{\sigma L_{r}} I_{d r}+s \omega_{s} I_{q r} \\
-\frac{R_{r}}{\sigma L_{r}} I_{q r}-s \omega_{s} I_{d r}+s \frac{M V_{s}}{\sigma L_{r} L_{s}}
\end{array}\right), \\
g_{u}(x)=\left(\begin{array}{cc}
\frac{1}{\sigma L_{r}} & 0 \\
0 & \frac{1}{\sigma L_{r}}
\end{array}\right) .
\end{gathered}
$$

The outputs to be controlled in the inner loop are defined as follows

$$
\begin{aligned}
& y_{1}=h_{1}(x)=T_{e m}=P \frac{M V_{s}}{\omega_{s} L_{s}} I_{q r}, \\
& y_{2}=h_{2}(x)=I_{d r} .
\end{aligned}
$$

For the outputs $y_{1}$ and $y_{2}$, their relative degrees $\rho_{1}$ and $\rho_{2}$ are equal to 1 . The resulting NMPC applied to the system (16) is given by

$$
u(t)=-G_{u}(x)^{-1}\left[\sum_{i=0}^{1} k_{i}\left(L_{f}^{i} h(x)-y_{r}^{[i]}(t)\right)\right]
$$

with $k_{0}=\frac{3}{2 T_{p 1}}, k_{1}=1, h(x)=\left(\begin{array}{ll}T_{e m} & I_{d r}\end{array}\right)^{\top}$, $G_{u}(x)=\left(\begin{array}{cc}P \frac{M V_{s}}{\omega_{s}} L_{s} \frac{1}{\sigma L_{r}} & 0 \\ 0 & \frac{1}{\sigma L_{r}}\end{array}\right), \quad y_{r}=\left(\begin{array}{c}T_{\text {em }-r e f} \\ I_{d r-r e f}\end{array}\right)$.

The d-axis rotor current reference is calculated to maintain at null value the stator reactive power flow to the grid.

\subsubsection{Outer control loop}

The speed controller in the outer loop is obtained by considering the mechanical dynamics of the DFIG. From equation (7), it follows that the mechanical equation can be expressed as

$$
\begin{aligned}
\dot{x}(t) & =f(x)+g_{u}(x) u(t)+g_{T}(x) T_{r}(t), \\
y & =h(x)
\end{aligned}
$$

where $x$ and $u$ are, respectively, the rotor speed $\Omega_{r}$ and the electromagnetic torque $T_{e m} . T_{r}$ is the aerodynamic torque and the output $y$ is the rotor speed. The vector function $f(x), g_{u}(x)$ and $g_{T}(x)$ are given by

$f(x)=-\frac{f_{r}}{J} \Omega_{r}, \quad g_{u}(x)=\frac{1}{J}, \quad g_{T}(x)=-\frac{1}{J}$.

The relative degree $\rho$ of the output $y$ is equal to 1 . Then, we shall have the optimal control input as

$u(t)=-G_{u}(x)^{-1}\left[\sum_{i=0}^{1} k_{i}\left(L_{f}^{i} h(x)-y_{r}^{[i]}(t)\right)+G_{T}(x) T_{r}(t)\right]$

with $k_{0}=\frac{3}{2 T_{p 2}}, k_{1}=1, h(x)=\Omega_{r}, y_{r}=\Omega_{r-r e f}$, $G_{u}(x)=\frac{\partial h(x)}{\partial x} g_{u}(x)=\frac{1}{J}, \quad G_{T}(x)=\frac{\partial h(x)}{\partial x} g_{T}(x)=-\frac{1}{J}$.

The rotor speed reference is given in the equation (4). In order to limit the control effort, the reference speed signal is passed through a second order linear filter given by

$$
F(s)=\frac{w_{n}^{2}}{s^{2}+2 \xi w_{n} s+w_{n}^{2}}
$$

where $w_{n}=5, \xi=1.2$.

\subsubsection{Nonlinear disturbance observer}

In this work, the aerodynamic torque is considered as an unknown disturbance, so the use of an observer is necessary to estimate it. Thus, the optimal control (20) becomes

$u(t)=-G_{u}(x)^{-1}\left[\sum_{i=0}^{1} k_{i}\left(L_{f}^{i} h(x)-y_{r}^{[i]}(t)\right)+G_{T}(x) \hat{T}_{r}(t)\right]$.

The nonlinear disturbance observer is developed in the same spirit as Chen et al [15]. An initial disturbance observer is given by

$\dot{\hat{T}}_{r}(t)=-\psi(x) g_{T}(x) \hat{T}_{r}(t)+\psi(x)\left[\dot{x}(t)-f(x)-g_{u}(x) u(t)\right]$ 
where $\psi(x)$ is the gain to be designed to ensure the stability of the observer. It is chosen as follows

$$
\psi(x)=\varphi_{0} \frac{\partial h(x)}{\partial x}
$$

with constant $\varphi_{0} \neq 0$.

Since there is no information about the derivative of the disturbance, we assume that

$$
\dot{T}_{r}=0
$$

Substituting equations (19) and (25) into (23), the observer error is described as

$$
\dot{\varepsilon}_{T}(t)+\psi(x) g_{T}(x) \varepsilon_{T}(t)=0
$$

where the observer error is $\varepsilon_{T}=T_{r}(t)-\hat{T}_{r}(t)$.

From equation (26), it can be shown that the observer is exponentially stable by choosing

$$
\psi(x) g_{T}(x)>0
$$

Using the Lie derivative (14) and equation (22), we get

$$
\begin{aligned}
\psi(x) g_{T}(x) & =\varphi_{0} G_{T}(x), \\
\psi(x) \dot{x}(t) & =\varphi_{0} \dot{y}(t), \\
\psi(x) f(x) & =\varphi_{0} L_{f} h(x), \\
\psi(x) g_{u}(x) & =\varphi_{0} G_{u}(x) .
\end{aligned}
$$

Substituting (22) and (28) into equation (23), we obtain

$$
\dot{\hat{T}}_{r}(t)=-\varphi_{0}\left(k_{1} \dot{\varepsilon}_{y}(t)+k_{0} \varepsilon_{y}(t)\right)
$$

where $\varepsilon_{y}=y_{r}(t)-y(t)$ is the speed tracking error.

Integrating equation (29), the estimated disturbance is calculated as follows

$$
\hat{T}_{r}(t)=-\varphi_{0}\left[k_{1} \varepsilon_{y}(t)+k_{0} \int_{0}^{t} \varepsilon_{y} \mathrm{~d} \tau\right]+\bar{T}_{r}(0)
$$

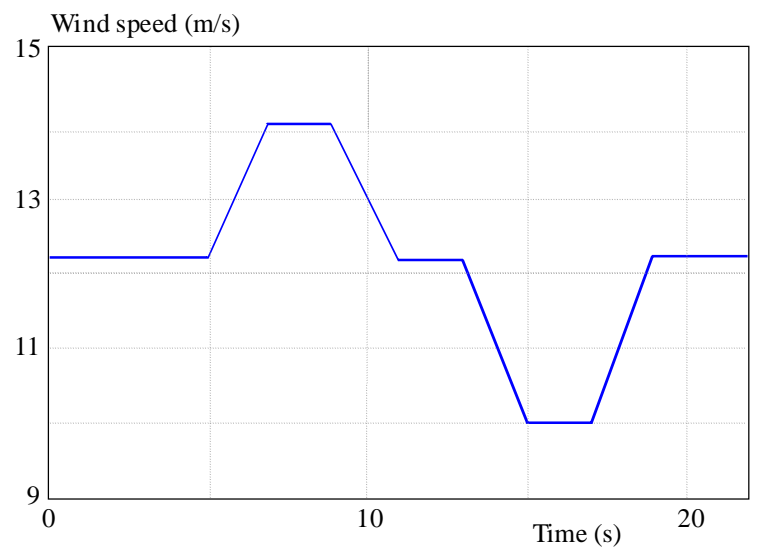

Fig. 5. Wind speed profile with $\bar{T}_{r}(0)=\hat{T}_{r}(0)+\varphi_{0} \varepsilon_{y}(0)$

If the initial value of the estimated disturbance $\hat{T}_{r}(0)$ is taken as

$$
\hat{T}_{r}(0)=-\varphi_{0} \varepsilon_{y}(0),
$$

then the estimated disturbance will be as follows

$$
\hat{T}_{r}(t)=-\varphi_{0}\left[k_{1} \varepsilon_{y}(t)+k_{0} \int_{0}^{t} \varepsilon_{y} \mathrm{~d} \tau\right] .
$$

Substituting equation (32) into (22), the control law becomes

$$
u(t)=k_{p} \varepsilon_{y}(t)+k_{d}\left(y_{r}(t)-L_{f} h(x)\right)+k_{i} \int_{0}^{t} \varepsilon_{y} \mathrm{~d} \tau
$$

where $k_{p}, k_{i}$ and $k_{d}$ are the proportional, integral and derivative gains, respectively.

$k_{p}=\frac{3 J}{2 T_{p 2}}-\varphi_{0}, \quad k_{d}=J, \quad k_{i}=-\frac{3 \varphi_{0}}{2 T_{p 2}}$.

\subsection{GSC control}

The GSC is connected to the electrical grid by an intermediary line characterized by a resistance $R_{f}$ and a reactance $X_{f}$ as shown in Fig. 4 .

In a $d-q$ reference frame related to the network angular speed $\omega_{s}$ equal to the synchronous speed, the electrical voltage equation is given by

$$
\begin{aligned}
\dot{x}(t) & =f(x)+g_{u}(x) u(t), \\
Y & =h(x)
\end{aligned}
$$

with $x=\left(\begin{array}{lll}I_{f d} & I_{f q}\end{array}\right)^{\top}, \quad u=\left(\begin{array}{ll}V_{m d} & V_{m q}\end{array}\right)^{\top}, \quad y=\left(\begin{array}{ll}P_{f} & Q_{f}\end{array}\right)^{\top}$.

The output vector y consists of the active and reactive power transferred to the grid by the GSC, while vector function $\mathrm{f}(\mathrm{x})$ and $\mathrm{gu}(\mathrm{x})$ are defined as

$$
\begin{gathered}
f(x)=\left(\begin{array}{c}
-\frac{R_{f}}{L_{f}} I_{f d}+\omega_{s} I_{f q}+\frac{1}{L_{f}} V_{f d} \\
-\frac{R_{f}}{L_{f}} I_{f q}-\omega_{s} I_{f d}+\frac{1}{L_{f}} V_{f q}
\end{array}\right), \\
g_{u}(x)=\left(\begin{array}{cc}
-\frac{1}{L_{f}} & 0 \\
0 & -\frac{1}{L_{f}}
\end{array}\right) .
\end{gathered}
$$

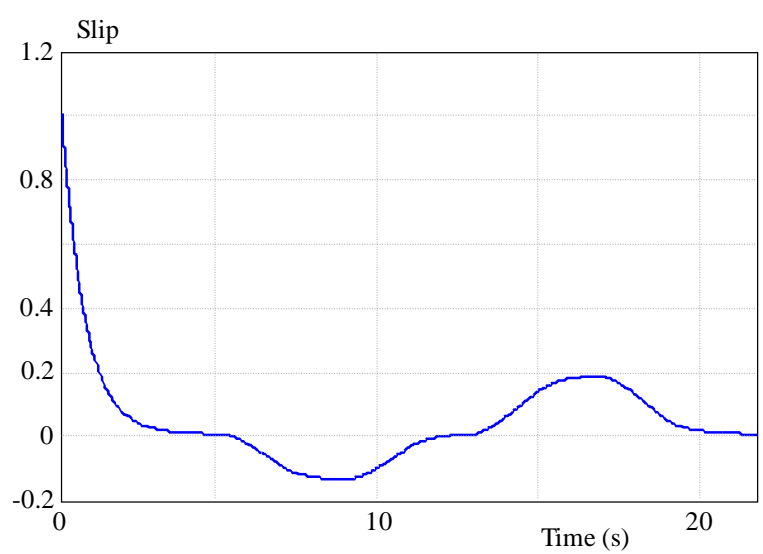

Fig. 6. DFIG slip 


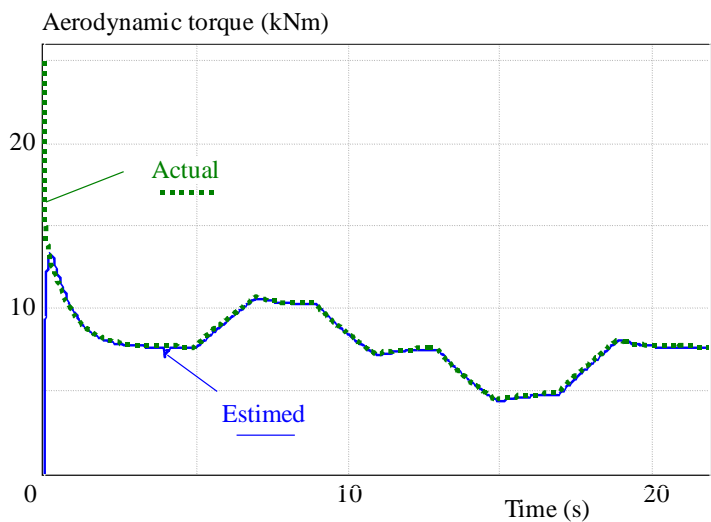

Fig. 7. Actual and estimated aerodynamic torque under DFIG's parameter variations: $25 \%$ in the rotor resistance at $t=4 \mathrm{~s}$ and $10 \%$ in the coefficient of friction at $t=16 \mathrm{~s}$

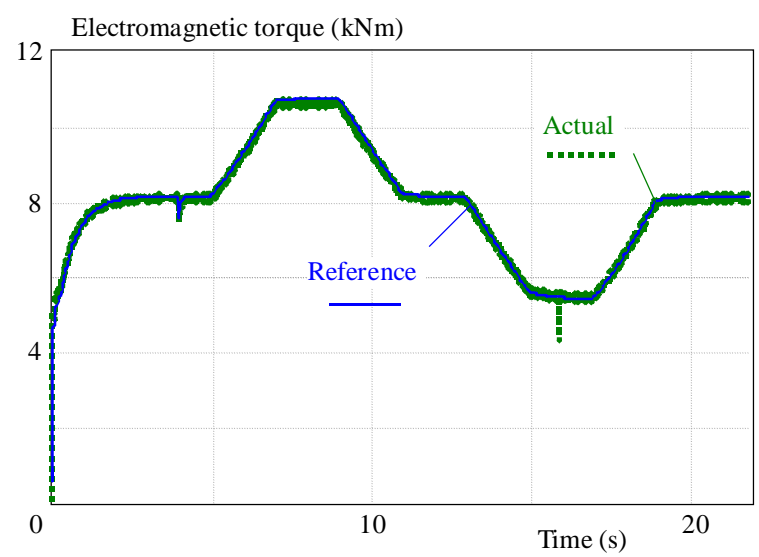

Fig. 9. Electromagnetic torque trajectory tracking: $25 \%$ in the rotor resistance at $t=4 \mathrm{~s}$ and $10 \%$ in the coefficient of friction at $t=16 \mathrm{~s}$

The outputs to be controlled are defined as follows

$$
\begin{aligned}
& y_{1}=P_{f}=V_{f d} I_{f d}+V_{f q} I_{f q}, \\
& y_{2}=Q_{f}=V_{f q} I_{f d}-V_{f d} I_{f q} .
\end{aligned}
$$

The resulting NPC applied to the system (34) is given by

$$
u(t)=-G_{u}(x)^{-1}\left[\sum_{i=0}^{1} k_{i}\left(L_{f}^{i} h(x)-y_{r}^{[i]}(t)\right)\right]
$$

with $k_{0}=\frac{3}{2 T_{p 3}}, k_{1}=1, G_{u}(x)=\left(\begin{array}{cc}-\frac{V_{r d}}{L f} & -\frac{V_{r q}}{L f} \\ -\frac{V_{r q}}{L f} & \frac{V_{r d}}{L f}\end{array}\right)$, $h(x)=\left(\begin{array}{c}P_{f} \\ Q_{f}\end{array}\right), y_{r}=\left(\begin{array}{c}P_{f-r e f} \\ Q_{f-r e f}\end{array}\right)$.

\section{SIMULATION RESULTS}

To evaluate the proposed controller performance, the drive system given in Figs. 4 and 5 are implemented in

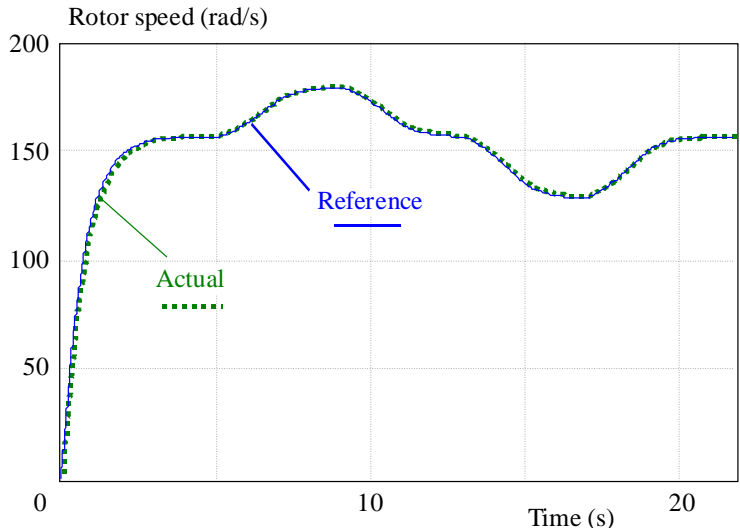

Fig. 8. Rotor speed trajectory tracking response: $25 \%$ in the rotor resistance at $t=4 \mathrm{~s}$ and $10 \%$ in the coefficient of friction at $t=16 \mathrm{~s}$

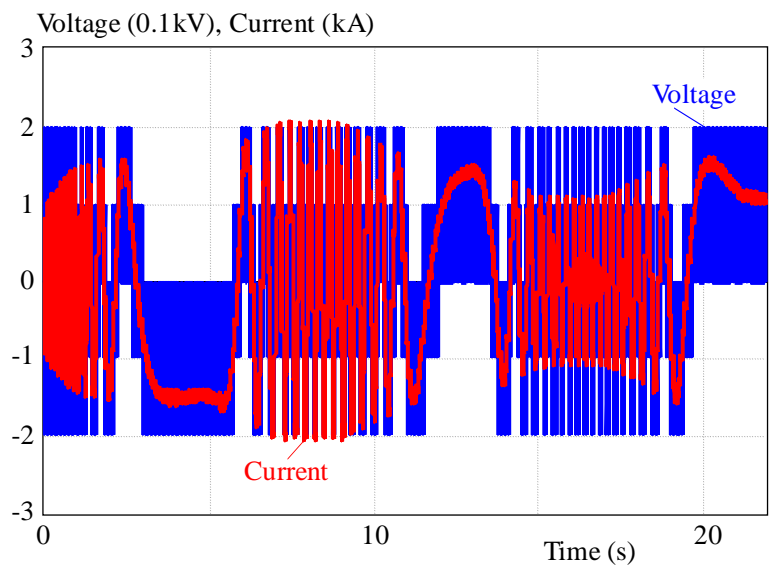

Fig. 10. RSC voltage and current

Matlab/Simulink in block diagram format. The predictive time are set to

$$
T_{p 1}=0.5 \mathrm{~ms}, \quad T_{p 2}=2 \mathrm{~ms} \text { and } T_{p 3}=1 \mathrm{~ms}
$$

The stability of the aerodynamic torque observer is guaranteed by choosing the value of $\varphi_{0}$ equal to -3 .

Results of simulation show good tracking capability of the proposed controller against the aerodynamic torque variations. The wind speed profile used in the simulation is illustrated in Fig. 5.

As seen in Fig. 7, the disturbance observer gives a good estimate of the aerodynamic torque. As NPC is a model-based approach, the accuracy of the DFIG parameters may influence the drive. The parameter variations introduced in the DFIG model are set to the following values: $25 \%$ in the rotor resistance at $t=4 \mathrm{~s}$ and $10 \%$ in the coefficient of friction at $t=16 \mathrm{~s}$. These variations are not taken into account in the controller. From Figs. 8 and 9 , we notice that very good tracking performances are achieved in terms of DFIG speed and electromagnetic 

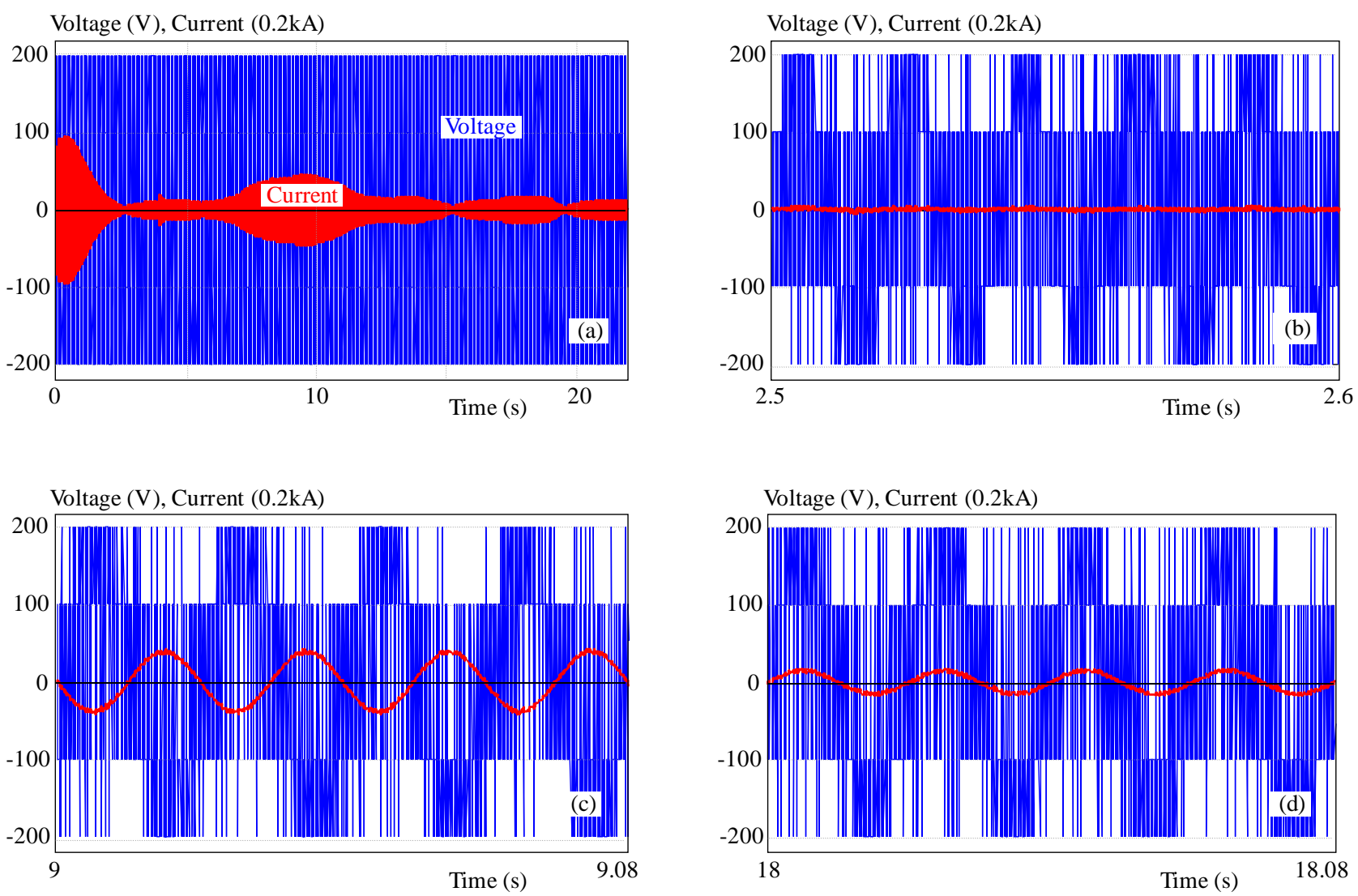

Fig. 11. (a) - GSC voltage $\left(V_{m-a}\right)$ and current $\left(I_{f-a}\right)$, (b) - Zoom rotor voltage and current for $s=0$, (c) - Zoom rotor voltage and current for $s<0$, (d) - Zoom rotor voltage and current for $s>0$
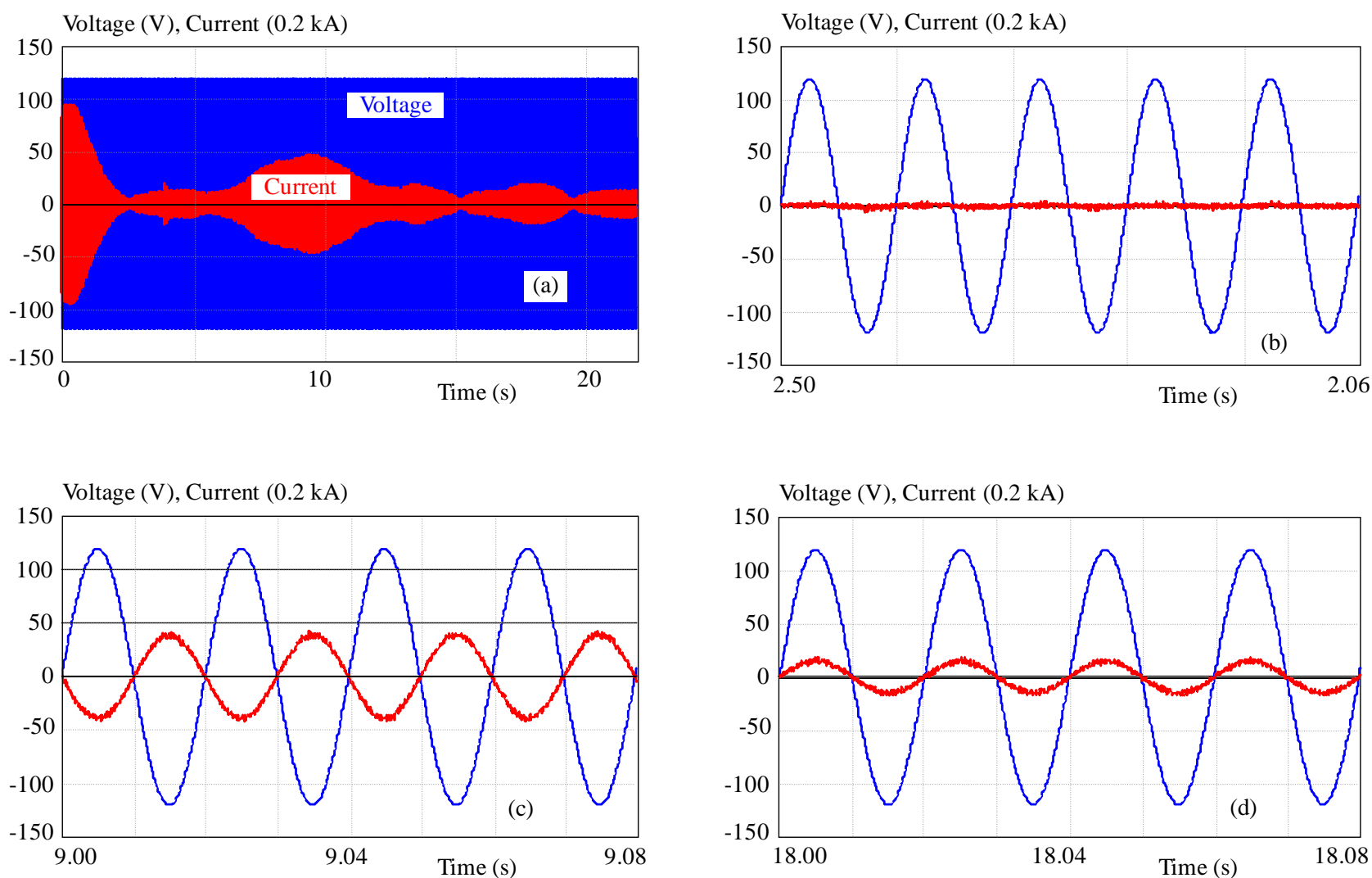

Fig. 12. (a) - Filter voltage $\left(V_{f-a}\right)$ and current $\left(I_{f-a}\right),(\mathrm{b})$ - zoom rotor voltage and current for $s=0$, (c) - zoom rotor voltage and current for $s<0$, (d) - zoom rotor voltage and current for $s>0$ 


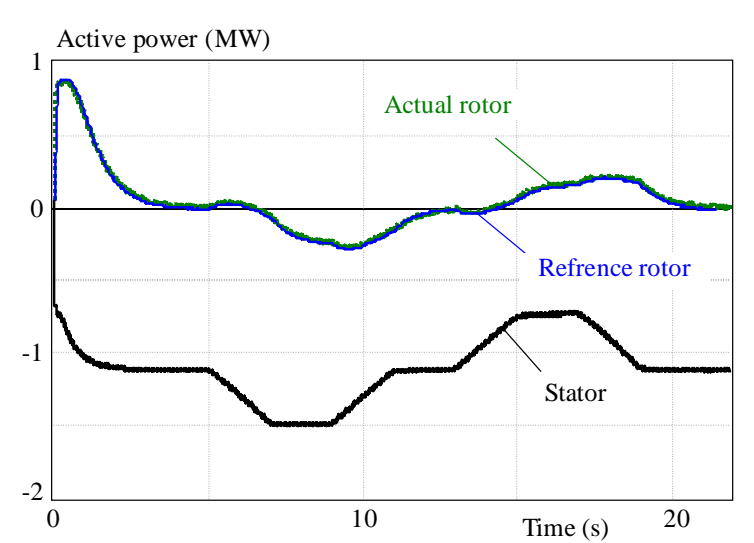

Fig. 13. Stator and rotor active power transited to the grid

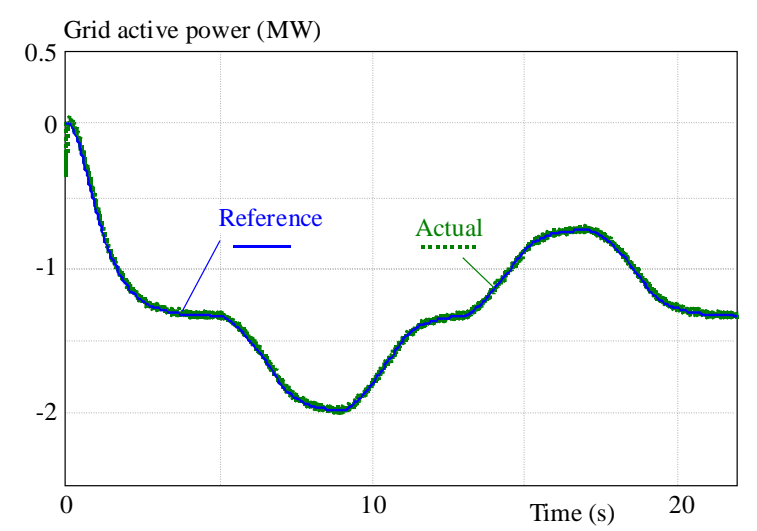

Fig. 14. Active power transited to the grid

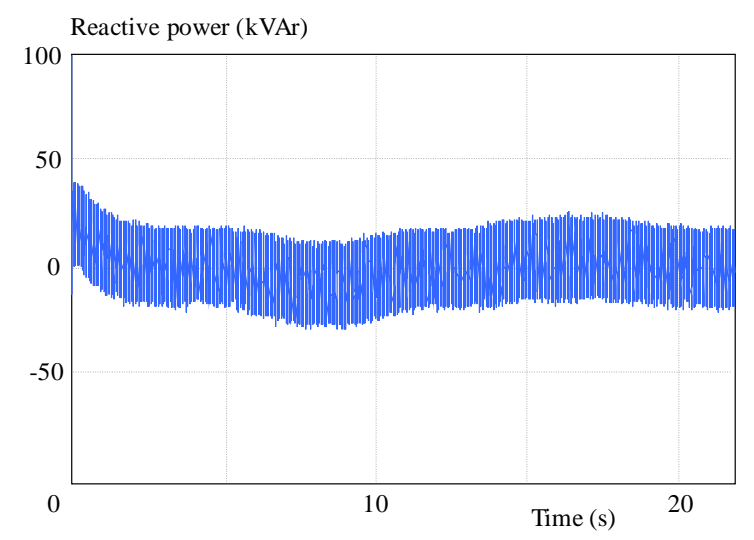

Fig. 15. Grid reactive power

torque with respect to wind and DFIG's parameter variations. The RSC voltage and current at sub-synchronous, synchronous and hyper-synchronous modes are plotted in Fig. 10.

The GSC voltage and current, at sub-synchronous, synchronous and hyper-synchronous modes, are plotted in Fig. 11. It is the same for the filter voltage and current in Fig. 12.

The stator and rotor active power transited to the grid are plotted in Fig. 13. The sense of drainage depends on the sign of the DFIG slip (Fig. 6). As shown in Fig. 14, the grid active power tracks perfectly its reference aiming to maximize the conversion efficiency. The grid reactive power is shown in Fig. 15. This power is maintained at zero value contributing to compensate the grid power factor. Therefore, the simulations results showed that the NPC offers excellent steady state and dynamic performance.

\section{CONCLUSION}

In this paper, a NPC strategy has been proposed for the wind energy conversion system (WECS) based on the DFIG. The control law is derived from optimization of an objective function that considers the control effort and the difference between the predicted outputs and theirs references. As a result, the control approach developed in this paper is easy to design and implement, car the optimal predictive control law is given an explicitly analytical form and on-line optimization is not necessary.

Simulation results have proven that the proposed controller is able to offer convergence of the system dynamic response to the reference values despite wind speed variations and DFIG's parameter variations. Indeed, the control strategy achieved a good reference tracking for rotor speed and electromagnetic torque at the steady state and transient responses. The NPC strategy is a good candidate for controlling the WECS based on a DFIG interconnected to the grid.

\section{Appendix}

1) DFIG: $1.5 \mathrm{Mw}, 690 \mathrm{~V}, 50 \mathrm{~Hz}, P=2, L_{s}=L_{r}=$ $0.0137 \mathrm{H}, M=0.0135 \mathrm{H}, R_{s}=0.012 \Omega, R_{r}=0.021 \Omega$, $P=2, f_{r}=0.0071, J=50 \mathrm{Kg} \mathrm{m}^{2}$.

2) Wind turbine: Turbine diameter $=60 \mathrm{~m}$, number of blades $=3$, hub height $=85 \mathrm{~m}, R=36.5 \mathrm{~m}$, gearbox $=90$.

3) Filter parameters: $R_{f}=1 \Omega, L_{f}=30 \mathrm{Mh}$.

4) Dc-link capacitor: $C=500 \mu \mathrm{F}, V_{d c}=400 \mathrm{~V}$.

5) Transformer : 120/690 V.

$\begin{array}{ll}\text { Nomenclature } \\ \text { RSC } & \text { Rotor Side Converter } \\ \text { GSC } & \text { Grid Side Converter } \\ P_{t} & \text { Aerodynamic power }(\mathrm{W}) \\ \rho_{a} & \text { Air density kg m } \\ v & \text { wind speed } \\ R & \text { Rotor turbine radius }(\mathrm{m}) \\ C_{p} & \text { Power coefficient } \\ C_{p-m a x} & \text { Maximal power coefficient } \\ \beta & \text { Blades pitch angle } \\ \lambda & \text { Tip-speed ratio } \\ \lambda_{\text {opt }} & \text { Optimal tip-speed ratio } \\ T_{t}, T_{r} & \text { Aerodynamic and Generator torque }(\mathrm{N} \mathrm{m}) \\ \Omega_{t}, \Omega_{r} & \text { Turbine speed, Generator speed (rad/s) } \\ \Omega_{r-r e f} & \text { Reference generator speed } \\ G & \text { Gear ratio } \\ P_{\text {grid-ref }} & \text { Reference grid active power (W) }\end{array}$


$\eta \quad$ System (wind turbine + DFIG) efficiency

$P_{s}, Q_{s} \quad$ Active and reactive stator power (W,var)

$P_{r}, Q_{r} \quad$ Active and reactive rotor power (W,var)

$P_{f}, Q_{f} \quad$ Active and reactive exchanged between

the filter and the grid (W,var)

$T_{e m} \quad$ Electromagnetic torque (N.m)

$V_{d r}, V_{q r}$ Two-phase rotor voltages (v)

$V \quad$ Stator voltages (V)

$I_{d r}, I_{q r} \quad$ Two-phase rotor current (A)

$R_{r}, L_{r} \quad$ Per-phase rotor resistance and self inductance

$M, P \quad$ Mutual inductance, Number of pole pairs

$J, f_{r} \quad$ Moment of inertia, coefficient of friction.

$\omega_{s}, \omega_{r} \quad$ Stator and rotor angular velocities $\mathrm{rd} / \mathrm{s}$

$s, \sigma \quad$ Generator slip and Dispersion ratio

$x, u \quad$ State vector and control output

$T_{r} \quad$ Disturbance

$\Im \quad$ Finite horizon cost function

$T_{p} \quad$ Predictive time

$\rho_{i} \quad$ Relative degree of the output $i$

$L_{f}^{k} h_{i} \quad$ The $k^{\text {th }}$ order Lie derivative of $h_{i}$

$R_{f}, X_{f} \quad$ Filter resistance and reactance

$\hat{T}_{r} \quad$ Estimated aerodynamic torque

$\varepsilon_{y} \quad$ Speed error

$\varepsilon_{T} \quad$ Observer error

$T_{p 1} \quad$ The predictive time (Inner control loop)

$T_{p 2} \quad$ The predictive time (Outer control loop)

$T_{p 3} \quad$ The predictive time (GSC control)

\section{REFERENCES}

[1] JIABING, H.: Direct Active and Reactive Power Regulation of DFIG Using Sliding-Mode Control Approach, IEEE Trans Energy Conversion 25 No. 425 (2011), 1028-1039.

[2] BELfEDAL, C. et al: Elsevier, Electric Power Systems Research 80 (2010), 230-239.

[3] SOARES, O.: Nonlinear Control of the Doubly-Fed Induction Generator in Wind Power Systemsjour Elsevier, Renewable Energy.
[4] VAlEnCIAGA, F.: Second Order Sliding Power Control for a Variable Speed-Constant Frequency Energy Conversion System, Elsevier, Energy Conversion and Management 51 (2010), 3000-3008.

[5] QIN, S. J.-BADGWELL, T. A. : A Survey of Industrial Model Predictive Control Technology, Elsevier, Control Eng. Practice 11 (2003), 733-764.

[6] GARCIA, C. E.-PRETT, D. M.-MORARI, M. : Automatica 25 No. 3 (1989), 335-348.

[7] CHEN, W.-H.: Optimal Control of Nonlinear Systems: A Predictive Control Approach, Automatica 39 No. 439 (2003), 633-641.

[8] HEDJAR, R.-TOUMI, R.-BOUCHER, P.-DUMUR, D. : Two Cascaded Nonlinear Predictive Controls of Induction Motor, IEEE Conference on Control Applications 1 (2003), 458-463.

[9] LIE, XU.—DAWEI, ZHI.—WILLIAMS, B. : Predictive Current Control of Doubly-Fed Induction Generators, IEEE Trans. Indus Electron. 56 (2009), 4143-4153.

[10] MOSTAFA, S.: Multiple Model Predictive Control for Wind Turbines With Doubly-Fed Induction Generators, IEEE Transactions on Sustainable Energy 2 No. 3 (2011), 215-225.

[11] TOMONOBU, S.: Output Power Leveling of Wind Turbine Generator for All Operating Regions by Pitch Angle Control, IEEE Trans. Energy Conversion 21 (2006), 467-475.

[12] CHEN, W.-H.-BALANCE, D. J.-GAWTHROP, P. J.-GRIBBLE, J. J.-O'REILLY, J.: Nonlinear PID Predictive Controller, IEE Proceedings Control Theory Application 146 (1999), 603-611.

[13] HOPFEnsperger, B.-ATKInSON, D.-LAKIN, R. : Stator-Flux-Oriented Control of a Doubly-Fed Induction Machine with and without Position Encoder, Inst. Elec. Eng. Proc. Electric Power Applications 147 No. 4 (2000), 241-250.

[14] YAmAmoto, M.-Motoyoshi, O.: Active and Reactive Power Control for Doubly-Fed Wound Rotor Induction Generator, IEEE Transactions on Power Electronics 6 (1991), 624-629.

[15] CHEN, W.-H. : Closed-Form Nonlinear MPC for Multivariable Nonlinear Systems with Different Relative Degree, IEEE Proceeding of the 2003 American Control Conference, vol. 6, 2003, pp. $4887-4892$.

Received 11 May 2013

Kamel Ouari, Mohand Ouhrouche, Toufik Rekioua, Taib Nabil - biographies not supplied.

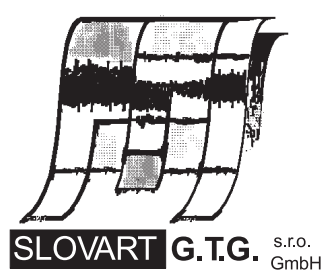

EXPORT - IMPORT
EXPORT - IMPORT

of periodicals and of non-periodically printed matters, books and CD-ROMs

Krupinská 4 PO BOX 152, 85299 Bratislava 5, Slovakia tel: ++421 263839 472-3, fax: ++421263839485 info@slovart-gtg.sk; http://www.slovart-gtg.sk

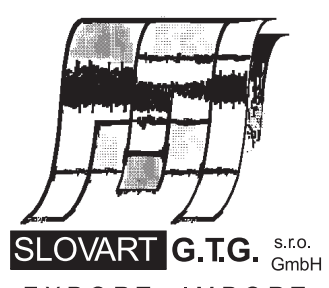

EXPORT - IMPORT 